\title{
Construções a partir do olhar masculino: as personagens cômicas femininas
}

\author{
Vera Collaço*
}

Nas décadas de 1930 e 1940 esteve em atividade, em Florianópolis, um grupo teatral denominado João Dall Grande Bruggmann, pertencente à União Beneficente e Recreativa Operária $(\mathrm{UBRO})^{1}$ cuja sistemática e intensa atividade teatral esteve voltada, essencialmente, para a classe trabalhadora da cidade. Neste artigo tenho por objeto de estudo os textos (dramaturgia) encenados por este grupo teatral. E dos textos encenados o foco de atenção está voltado para o conjunto textual cômico, do qual foi possível recuperar durante a fase de pesquisa um total de doze comédias, e estas se subdividiam em comédias de um ato, predominantes entre as encenações da União Operária, comédias de dois e três atos. ${ }^{2} \mathrm{E}$, num recorte mais preciso a análise se volta para a compreensão do papel e da relevância das personagens femininas no corpus cômico encenado pelo grupo João Dall Grande Bruggmann.

Este conjunto cômico apresenta, pelo menos, dois desequilíbrios bastante visíveis, com relação à organização do material textual, isto é, quanto à distribuição das cenas e das falas entre as personagens. Num olhar quantitativo percebe-se que as mulheres ocupam um espaço menor nesta dramaturgia. Poucos são os textos que possibilitam a cena ser ocupada apenas para o diálogo entre mulheres, em contraposição as inúmeras cenas construídas a partir do diálogo estabelecido entre dois ou mais homens. E mesmo nas cenas em que o diálogo se estabelece a partir da relação entre homens e mulheres, o predomínio quantitativo das falas é masculino, e não apenas em maior número, mas também na sua importância, na qualidade desta fala para o desencadear da ação ou pelas "verdades" nelas contidas.

\section{Sobre os conteúdos cômicos}

Predomina nesta dramaturgia cômica a exaltação dos valores burgueses de família e da instituição que a constitui e a solidifica, o casamento, bem como questões relativas a dinheiro. Como observa Cláudia Cecília Alatorre (1986: 67), "la comedia hace la apología de los valores que garantizam el bienestar social, o cuando menos, lo que la burguesía entiende como tal cosa". Seus enredos giram em torno de namoros, amores contrariados, casamentos, o cotidiano familiar, a convivência com os criados, dificuldades financeiras e heranças. Neste sentido, este corpus textual pode ser dividido em dois grandes blocos temáticos, um que expõe os problemas no casamento e outro que trata de amores que se canalizam para o casamento, enaltecendo, conseqüentemente, os valores implícitos a esta instituição, segundo a moral burguesa, ou seja, a virgindade, a fidelidade e o respeito à instituição matrimonial. Estes textos fazem à

\footnotetext{
* Professora efetiva no Departamento de Artes Cênicas, do Centro de Artes/Universidade do Estado de Santa Catarina; Doutora em História Cultural - Universidade Federal de Santa Catarina, Tese sobre O Teatro da União Operária: Um palco em sintonia com a modernização brasileira, 2004
} 
defesa do casamento monogâmico e indissolúvel, dentro da perspectiva cristã de família, e cujo fim essencial é o de gerar, criar e educar a descendência.

\section{As personagens do imaginário cômico}

As primeiras informações sobre as personagens, de um texto dramático, aparecem, normalmente, após o título, numa listagem nominal. Estes primeiros dados fornecem um quantitativo com relação ao número de personagens que compõem o universo dramático. Neste sentido, as pequenas comédias possuem um número menor de personagens, em média três ou quatro, enquanto que as comédias maiores são compostas de oito a dez personagens. Deste quantitativo aparece outro indicativo que se refere à distribuição destas personagens por gênero, e neste aspecto o conjunto cômico é constituído, majoritariamente, por personagens masculinas. Apenas na comédia Não me Contes esse Pedaço se inverte esta predominância masculina. $\mathrm{O}$ texto é construído em torno de cinco mulheres e quatro homens. $\mathrm{O}$ equilíbrio aparece nos textos Cala a Boca, Etelvina, constituído de cinco homens e cinco mulheres e no texto O Visconde de Rosa Branca, que tem dois homens e duas mulheres.

Os autores das comédias aqui analisadas fornecem poucas informações sobre a individualidade destas personagens, e quando o fazem, estes dados se referem, geralmente, ao estado civil - casado (a), viúvo (a), solteiro (a), não tendo neste conjunto nenhuma personagem "separada" ou desquitada - às relações de parentesco, ao nome, idade e muito raramente à atividade profissional.

Na questão de parentesco chama a atenção neste conjunto à ausência da figura materna. O núcleo familiar, em sua grande maioria, é constituído de um pai viúvo e seus filhos, de preferência filhas para as quais o pai atua como o provedor, guardião de sua moral e projetor de seu futuro, o que implica em conseguir-lhe um marido, ou seja, em encontrar um substituto para o seu papel de pai. ${ }^{3}$ Nestes casos a filha assume o papel reservado à mãe que é o de cuidar do lar. A ausência desta personagem não se faz sentir nas falas das (os) filhas (os) e nem dos viúvos, a vida corre perfeitamente bem sem este elo afetivo e relacional nas famílias destas comédias, o que põe em destaque, como conseqüência, a importância da figura paterna na estruturação e manutenção da família.

\section{Os condutores da ação cômica}

Nestas comédias os sujeitos que conduzem a ação, que protagonizam os textos, são todas personagens masculinas, pai, filho, marido, sogro, possível amante, pretendente ou namorado, e o objeto de seu querer é a realização amorosa, ou seja, uma figura feminina. A este querer soma-se também, em alguns destes textos, a busca por dinheiro, seja através do casamento ou de outros mecanismos como o jogo. A exceção fica por conta do texto A Sogra, que tem em Quitéria, a sogra, a personagem principal. Mas esta personagem está longe de ser um modelo de feminilidade, pois o autor ao zombar desta figura a fez pensar e agir como homem, ou seja, mandando e demandando no marido de sua filha. "Quitéria - [...] A natureza enganou-se comigo. Eu nasci, mas foi para homem!"4

\footnotetext{
U 92 - Dezembro 2006 - № 8
} 
Como estes textos têm sua intriga centrada em questões amorosas, os oponentes, ou seja, as personagens antagonistas, que se opõem à concretização do desejo dos protagonistas, são em sua maioria outros homens, que também tem por meta o mesmo objeto de querer, ou que se opõem ao querer dos protagonistas. Mesmo no texto A Sogra, cuja protagonista é uma mulher os seus antagonistas são homens, que não aceitam sujeitar-se ao seu querer.

\section{O perfil das personagens cômicas femininas}

Se o texto didascálico já é sucinto em apresentar dados sobre o trabalho masculino, no caso das personagens femininas este dado inexiste, ao lado dos seus nomes. Quando há alguma indicação, esta se refere: Clara - mulher de Fernando, Amélia - filha de Baldoméro, ou seja, se define o papel da mulher a partir de sua relação de dependência da personagem masculina. ${ }^{5}$ Estas personagens femininas, portanto, são construídas a partir de discursos masculinos, que determinam quem são e o que devem fazer as mulheres.

Em nenhum dos textos, aqui analisados aparece à figura feminina em atividades profissionais. Seu espaço restringe-se ao mundo doméstico e sua função básica é a de ser dona-de-casa. Neste sentido devem ser compreendidas as personagens femininas que atuam como criadas em casas mais abastadas, elas não estariam exercendo uma profissão e sim executando tarefas domésticas: "O trabalho feminino fora da esfera doméstica, especificamente as mulheres dos segmentos populares, e aceito "como natural" e necessário no século XIX, começou [no século $X X]$ a ser encarado como um mal antinatural e lamentável (ainda que necessário), que punha em risco a estabilidade familiar e a ordem social e política." (Besse, 1999: 8-9).

As restrições profissionais às mulheres ganharam forte acento no governo Vargas, que com sua "legislação protetora' e sua ênfase na família, restringiu o emprego feminino a setores e a turnos 'adequados' e, não por coincidência, menos remunerados, fundamentando assim a subordinação das mulheres aos homens por via da dependência econômica”. (Soihet, 1997:286). Embora os lares fossem, legalmente, chefiados pelos homens, às mulheres cabia um "importante papel" de serem as responsáveis pelo equilíbrio familiar e tranqüilidade do homem, para que este pudesse produzir mais e melhor pela pátria.

A mulher, portanto, teria "sua área de atuação no lar" e deixaria para os homens as preocupações econômicas. Este modelo estava mais relacionado com as mulheres de classe média, pois como observa Rachel Soihet (1997:285), "as mulheres dos segmentos populares sempre trabalharam, tanto na cidade como no campo [tais estereótipos se pautam] na invisibilidade atribuída ao trabalho doméstico".

Quanto à representação do papel da "mãe", ausente nas pequenas comédias, aparece nas comédias de dois ou três atos, em dupla imagem: mãe-esposa e mãe-sogra. Estas "mãesesposas" aparecem em relacionamento com suas filhas solteiras e, principalmente, com os seus maridos, e são caracterizadas como mulheres que desejam mandar nos filhos e no marido, ou seja, querem assumir o papel que estava destinado aos pais-maridos.

Juvêncio Cobra (puxando-a pelo braço) - Rosa! Ó Rosinha!... Tem modo... 
Rosa Cobra (voltando-se furiosa e agarrando uma forma de sapato) - É revoltante esta violência! Vou mostrar com quantos paus se faz uma canoa.

Juvêncio (entrando apressado debaixo da mesa) - Mulher! Olha o que fazes ...

Rosa - Raspa-te daí, que eu quero por tua cara na forma...

Juvêncio (sério) - Rosa! Ó Rosa! Diga-me uma coisa: quem manda em casa? É o marido ou a mulher? (cara de choro)

Cecília (para a mãe) - Mamãe! Mamãe! Respeita a presença de um estranho...

Rosa (para a filha) - Também tu, lambisgóia?! Já viu pinto entrar em briga de galos?! (deixa a forma cair). ${ }^{6}$

Estas mães-esposas quando extrapolam o seu papel social, são retratadas como ardilosas e enganadoras, como é o caso de Rosa Cobra, que fez todo este escarcéu, que é diário, porque o marido estava comprando bilhetes de loteria e jogo do bicho, mas ela também quando sozinha com o "agente lotérico" faz a sua fezinha, às escondidas de seus familiares. E quem fica satisfeito é o vendedor do jogo. "Ricardino - É a melhor freguesia que tenho, esta boa família. É verdade que todos jogam às ocultas. Mas jogam. Se até o gato não joga é porque no jogo não entra rato." $\mathrm{Ou}$ ainda como a mãe Gertrudes, do texto Não me Contes esse Pedaço, que ensina uma de suas filhas, Nair, a ser dissimulada e parecer o exemplo de castidade e candura para conseguir "agarrar" um marido.

A exceção a este protótipo autoritário de mãe-esposa está na personagem Rosa, de $\mathrm{O}$ Interventor. Ela é uma mãe e esposa dedicada aos desejos e caprichos de seu marido, e sua participação na trama é a de conciliar, harmonizar ou amenizar os possíveis conflitos familiares. Com conseqüência, é uma figura que não aparece, se coloca como pano de fundo.

Se as mães-esposas aparecem com um perfil distorcido, quando desejam ou vão além de sua "esfera própria", as "mães-sogras" são retratadas como o pesadelo vivo de seus genros. Horácio Nunes Pires dedica um texto inteiro a ridicularizar e a demonstrar os malefícios que a sogra causa aos jovens casais. Fernando, recém casado com Mariquinhas, caracteriza sua sogra como: "As sogras têm sete fôlegos, como os gatos. [...] Sogra não morre. [...] A sogra é a serpente do paraiso conjugal. [...] A febre amarela. [...] A sogra é o demônio do lar doméstico: decompõe o genro e ensina a filha a decompor o marido." 8

Horácio Nunes Pires estava sintonizado com as problemáticas de seu tempo e o seu texto A Sogra, de 1883, debate, justamente, a família moderna, que, segundo Joana Maria Pedro (1990: 113-105), se configura, no Brasil, no século XIX, centrada na trilogia pai-mãe e filhos. Este "aburguesamento da família" pode ser observado na cidade de Nossa senhora do Desterro na segunda metade do século XIX. Na família moderna qualquer presença estranha a esta trilogia, "era considerada estorvo. Neste caso qualquer parente, e inclusive a sogra, também, deveria ser considerado intrusa". (Pedro:1990:113) E este estorvo que era considerada a sogra podia representar a destruição do lar e provocar grandes aborrecimentos. Acompanhando o estudo de Joana Maria Pedro (1990:114) e cotejando com o texto de Horácio Nunes Pires, 
percebe-se como esta personagem podia representar a desestruturação de um novo lar: "De que forma um homem recém-casado poderia impor toda sua "natural" autoridade sobre sua esposa, se tivesse a companhia constante ou mesmo apenas freqüente da sogra? No novo lar, na territorialização dos espaços da nova família, a sogra representa mais poder para a esposa. A sogra é a mãe velha que pode representar uma transmissão autárquica de saberes para a filha, conhecimentos práticos, que, se por um lado podem significar melhor conforto para o jovem esposo, representam também fontes de poder para a jovem esposa."

O saber da mãe velha ao ser transmitido para a filha recém-casada é o motivo de desespero de Fernando.

Fernando - Quando me casei, minha mulher era dócil, meiga, obediente, desprovida de vaidades, inimiga do luxo. Mas porque?... Porque se achava longe da mãe. [...] Mas, logo que minha sogra voltou, as coisas começaram a mudar. Principiaram os enfados [...] as respostas tortas. Depois vieram as exigências [...]. ${ }^{9}$

A sogra representava o elemento esclarecedor e cúmplice da filha-esposa, e com isso desequilibrava a estrutura de poder do marido. "Aliás era comum os maridos culparem as sogras pelas rebeldias e desobediências das esposas. [...] a esposa permanece a 'santa', porém 'ingenuamente' se deixa influenciar pela 'bruxa' que é a sogra”. (Pedro, 1990:114)

Amenizadas em suas posturas, mas com o mesmo perfil e significando os mesmos aborrecimentos aparecem as sogras em Cala a Boca, Etelvina, escrita em 1925, e a futura sogra em Não me Contes esse Pedaço, escrita em 1929.

Esta desqualificação da sogra do marido "serviam para reduzir a influência desta sobre a filha. Ao desqualificar os saberes da velha mãe, e ao ridicularizá-las estão, ao mesmo tempo, denunciando o seu poder. [...] Nos parece que, diante das dificuldades de impor sobre as mulheres toda a sua 'natural autoridade' os homens culpavam as sogras, e pelo menos na imaginação, através das páginas dos jornais [e das peças de teatro], vingavam-se." (Pedro, 1990:115-116).

Quanto às jovens esposas, mesmo quando não estavam sob a influência da sogra, tendiam, nestes textos, a apresentar uma certa rebeldia transgressora que provocava situações de conflito no casamento, e cuja origem, na visão destes autores-homens, estava na falta de autoridade dos maridos para conter estes desvios comportamentais de suas esposas, e isto ocorria porque os homens, Alberto - [...] Amo minha mulher o mais que é possivel amar-se! E esta quase adoração que lhe consagro, faz com que seja ela e não eu quem mande nesta casa!... É preciso por cabo a isto! ${ }^{10}$. Na perspectiva destes autores, os homens devem amar suas esposas, mas sem perder sua autoridade, e devem exigir que esta seja o que se espera de uma boa esposa, pois, "entre os deveres familiares das mulheres - e acima de tudo - estava o de serem permanentemente agradáveis a seus maridos. [...] Acima de tudo, exigia-se que a esposa dedicasse toda a sua atenção ao marido, demonstrando que vivia apenas para ele". (Besse, 1999:79).

A esposa-mulher que não se adaptasse ao seu papel social estaria sujeita ao abandono, a solidão e a miséria. Esta situação está exposta em Choro ou Rio? 
Alberto - [...] Ou a senhora será para mim uma esposa terna e dedicada, sem jamais me importunar com as lembranças dos seus enfadonhos e turbulentos animais ou eu faltarei a fé jurada, abandonando-a, fugindo depois para bem longe daqui, a esquecer-me de que sou casado. [...] A senhora cuida mais dos animais do que do seu marido! ${ }^{11}$

A rebeldia destas esposas se manifesta em sair, constantemente, segundo a perspectiva de seus maridos, de casa com ou sem o seu consentimento, em serem vaidosas demais, ou como a personagem Clotilde que se envolve numa sociedade protetora dos animais e não numa associação de caridade, que seria o "correto" e o desejo de seu marido, ou ainda na intransigência e no excesso de nervos, como os da personagem Zulmira, de Cala a Boca, Etelvina. Tudo isso pode arruinar a felicidade de um jovem casal.

Quanto às jovens solteiras, todas elas possuem como ponto em comum o desejo de se casar. E, embora todas desejem poder escolher os seus futuros maridos, essas jovens se adaptam ao projeto paterno, que acaba direcionando suas escolhas. A única exceção está no texto Grandes Manobras, no qual a personagem Mariquinhas não aceita a imposição paterna. "Mariquinhas - Meu pai, eu só me casarei por minha vontade. [...] Quero casar-me, e hei de casar me com o sr. Malaquias, e já o previno, meu pai, que si quiser obrigar-me, fujo de casa."12

Algumas das jovens deste conjunto cômico apresentam um comportamento "moderno", como ficar namorando no quintal, nas janelas de casa, ir ao cinema e fazer passeios para serem vistas e olhar os rapazes, usar gírias e expressões francesas, e, principalmente, querer escolher seus maridos. Embora "modernas" e namoradeiras, estas jovens não colocam em risco a sua "pureza", ou seja, sua virgindade, pois isso colocaria a perder a sua honra e o seu desejo de casamento. Estas jovens são traçadas como sonhadoras, influenciadas pelo cinema e pelos romances, mas, no fundo, todas possuem um só desejo, o de casar-se, e o príncipe encantado acaba sendo, na maioria dos casos, o homem escolhido por seus pais.

A aceitação quase unânime, por parte destas jovens, do projeto paterno, se deve ao seu desejo de casar e na crença de que o amor pode nascer da boa convivência com o marido. Essa realidade se afirma na voz de uma mãe-esposa, ao aceitar o encaminhamento que o marido dá a filha do casal. "Rosa - [...] Eu também quando era moça não queria casar com o Luiz e no entanto, depois de casada, acabei gostando dele." 13

E também na fala da jovem que observa o que se passa a sua volta. "Amélia - [...] Se o homem não for de todo desajeitado, esta dito, caso-me com ele! D. Rita casou assim, e tem sido muito feliz! Se eu for esperar pelo Zé, estou arranjada!" ${ }^{14}$

Ainda procurando reforçar que a escolha paterna é acertada, em dois destes textos se apresenta a jovem solteira que aceita, sem grandes vontades, a escolha paterna, e logo a seguir, depois de casada, está totalmente apaixonada por esse marido. ${ }^{15} \mathrm{Ou}$ seja, na perspectiva masculina dos autores destes textos, as mulheres são sonhadoras demais, e cabe aos homens, primeiro ao pai e depois ao marido, dar-lhes o norte, o encaminhamento na

- Dezembro 2006 - № 8 
vida, pois às mulheres dependem do cérebro e do braço masculino, devido a sua fragilidade e incapacidade de tomar decisões, pois elas são eternas crianças.

O casamento além de ser o meio pelo qual a família e a honra da filha solteira ficava preservada, era também, "para as famílias de fora da elite, com pretensões a ascender, (...) um meio de mobilidade social ascendente e de segurança financeira para toda a família”. (Besse, 1999:54). Esta situação está colocada em A Espada do General.

Amélia - Mas isso não impede que o meu coração escolha o seu eleito. Baldoméro - Não, por certo. Porém, o que vais tu esperar de um tipinho que não tem uma gata para puxar pela cauda? ... O meu desejo é te casar o mais depressa possível, mas com um homem que tenha "milho"... De milho é que nós precisamos.

Amélia - O papá tem cousas!... Nós não somos burros para comer milho!

Baldoméro - Não é desse que eu falo. Refiro-me ao milho dourado, dinheiro... aquilo com que se compra feijão, arroz, carne, e tudo que é bom e gostoso. ${ }^{16}$

O universo feminino é, ainda, acrescido pela figura da criada doméstica. Esta personagem não possui nem a dimensão e nem a interferência na ação de seu correlato masculino. Elas podem ser cúmplices da patroa, mas sempre com vistas a melhor servir ao patrão. Esta personagem é bastante característica de um contexto social brasileiro, como analisa Susan Besse (1999:9): "Alem do trabalho fabril 'feminino', o serviço doméstico continuava a proporcionar outra grande fonte de emprego para as mulheres pobres das cidades. Enquanto as empregadas domésticas liberavam as mulheres de classe média para exercer suas carreiras, elas próprias permaneciam presas na esfera doméstica sob a tutela de suas patroas mais ricas" ${ }^{17}$

Enquanto os criados procuram sempre tirar proveito da situação em que lhes colocam os seus patrões, mas são construídos como pessoas de bom caráter e honestas, as criadas apresentam um perfil mais conservador que os criados, e reprovam as condutas "modernas" de suas patroas: "Rosa (só) - [...] A senhora sair de trem de aluguel, sem dizer nada ao senhor!" 18

A exceção a este perfil de criada aparece no texto Cala a Boca, Etelvina! A criada, Etelvina, que forma par romântico com outro criado, o Manoel, num contraponto ao casal burguês que protagoniza a comédia, é uma das responsáveis pelas cenas mais hilariantes que ocorrem no texto, devido a uma série de equívocos, pelo seu linguajar, repleto de gírias e mal elaborado, e pelos seus modos, principalmente à mesa.

Libório - [...] Mas se meter a faca na boca, lamber os dedos,deitar-se em cima da mesa...

Etelvina - O sr. pensa que eu não sei comer numa mesa? Lá na cozinha, com as outras, é que a cousa é a bessa. Mas, quando a zona é distinta, o macaco é outro. ${ }^{19}$ 
Apesar do seu "esforço", não consegue esconder sua condição social diante daqueles a quem ela representa o papel de patroa.

Baronesa - [...] Onde foi o Adelino encontrar esta menina?

Macário - [...] Ele me mandou dizer que se casava com uma moça de boa família, pobre, sim, mas honesta e muito bem educada.

Baronesa - Quanto a honestidade, nada posso ainda dizer; mas a respeito de educação, o que me parece é que ela a recebe no meio da rua.

Macário - E uma das mais baixas. Não viu os seus modos agora na mesa?

Baronesa - E a linguagem que ela fala? Eu nunca ouvi coisa igual. ${ }^{20}$

Etelvina também sonha em casar e ter condições similares à classe média. Para tanto, deseja também ter criadagem ao se casar. Ela critica sua patroa por exigir demais dos criados. E afirma que quando tiver criados agirá diferentemente. Mas o autor, ao zombar deste desejo de ascensão social, mostra o comportamento de Etelvina, quando "representa" o papel de patroa.

Adelino (desesperado) - Que é que você foi fazer, rapariga?

Etelvina - Não fiz nada de mais. A Maria saiu fora da linha e eu sapequeilhe o braço ... Foi só isso [...]. ${ }^{21}$

Na perspectiva desses autores cômicos os segmentos populares não tinham a menor capacidade de adquirir um mínimo de postura, hábitos e de comportamento das classes mais ricas, mesmo quando colocados em outro contexto social, pois lhe faltava o essencial, uma boa educação.

\section{O aprendizado através do riso}

Nas narrativas conservadoras e moralistas, a exemplo destas comédias se recompensa às personagens que agiam conforme os padrões impostos pelo grupo social dominante e se castiga as que transgridem as normas e padrões de valores e comportamentos considerados atípicos e inconvenientes.

Para que possa atingir o seu fim moralizador de corretor de desvios, a personagem cômica deve afrontar o "marco moral de su momento histórico y que, por outro lado, quede claramente el marco legal de los valores ideales de esa sociedad. Es decir, 'lo que no debe hacer' enfrentando a 'lo que si debe hacer”.(Alatorre, 1986:68).

Ao defender os valores éticos e morais da burguesia estes textos apresentam personagens transgredindo em aspectos fundamentais para a moral dominante, no momento histórico em que foram encenados na União Operária. Sua transgressão pode colocar em risco o "caráter sagrado" do casamento, da família, da honra, do valor do trabalho, e do dinheiro que deve ser ganho, honestamente, e pelo trabalho. 
O texto A Sorte Grande é o que expõe, deste conjunto textual, o maior número de transgressões desejadas e executadas por um grupo de personagens. Dentre os inúmeros desvios apresentados pelas personagens - o marido desejar separar-se de sua esposa, não considerar a mulher como companheira de vida, a mulher mandar no marido, os pais concordarem num casamento sem amor para sua filha - a maior transgressão da família Cobra é ser viciada em jogo - loteria e do bicho - e de Juvêncio Cobra o seu desamor pelo trabalho, a ponto de queimar sua casa e sua oficina ao se pensar rico, e, ainda mais, o seu desejo de ganhar dinheiro, ficar rico, através do jogo e não pelo esforço de seu trabalho.

Por isso sua punição, bem como de sua família, foi exemplar, pois ele não ganhou na loteria, ou seja, não tirou a sorte grande, tudo não passou de uma armação do pretendente rico, "filho do capitalista", que desejando casar com Cecília Cobra, mas impedido por ser rico, elabora uma trama do falso bilhete premiado junto com o vendedor de loteria. Juvêncio não o aceitava como genro porque temia ser rejeitado no futuro, por este genro, pelo fato de serem pobres. Como punição ele perde tudo - a casa, a oficina, tem que ficar com sua mulher e ainda aceitar que sua filha case com o "filho do capitalista", de quem agora, depende economicamente.

A canção final deste texto sintetiza a moral e os ensinamentos que deveriam atingir o corpo social - os espectadores da União Operária -, não apenas com relação a esta peça, mas também no que diz respeito às demais comédias, visto que expõe, resumidamente, os valores morais e os comportamentos que deveriam ser assimilados como positivos e rejeitados como negativos por este corpo social.

Sorte grande, sorte grande...

Bobo é quem nela acredita.

Loteria e bicharia...

Oh! Que esparrela maldita!

O homem já nasce rico,

O homem nasce casado...

Toda ambição é maldita,

Só o trabalho é honrado. ${ }^{22}$

As personagens, deste corpus textual, também são punidas por sua prepotência e egoísmo, principalmente quando estes vícios sociais colocam em risco a composição de uma família, como ocorre em Casar para Morrer, onde o pai Jacinto, não querendo mais ficar preocupado com sua filha solteira arranja-lhe um marido que esteja à beira da morte. Assim, ele não teria o incomodo de ter crianças em casa e teria a filha para cuidar dele. Mas o marido que ele arruma está "morrendo" por causa de fome e não por doença. O "marido" ao comer bem fica curado, e acaba conquistando o amor de sua "esposa”. O pai, por punição, tem que aceitar e pedir que o jovem casal o perdoe e o acolha em seu futuro lar. 
Quanto às mulheres que apresentam certa rebeldia transgressora, sejam jovens esposas ou as moçoilas solteiras, ao correrem o risco de perder sua segurança representada pela figura masculina, do pai ou do marido, retrocedem em suas condutas e aprendem que o seu papel social é o de serem boas donas de casa e, principalmente, o de serem obedientes aos desejos de seus pais ou de seus maridos. E às sogras, estas perversas criaturas, são punidas com puxões de orelhas, purgantes, e com a devida autoridade do marido e do genro, que devem impor-lhe limites muito estreitos.

A personagem transgressora é punida, sem que perceba, ao rirmos dela, ao ridicularizála. "El castigo es moral. La risa significa descrédito, desconfianza, burla, ver minimizado al otro; para el protagonista es verguenza y escárnio". (Alatorre, 1986:68).

Ao lado dessas personagens "desviadas", esse corpus textual representa personagens virtuosas, respeitosas das leis e valores morais e comportamentais que a sociedade burguesa considera adequados, e seus exemplos se contrapõem aos vícios e erros das personagens transgressoras e, conseqüentemente, são recompensadas ao final do texto, seja pelo casamento ou pela harmonização no ambiente familiar, e no caso dos homens, por adquirirem o domínio da casa e a autoridade ante suas esposas.

O riso que advém de uma situação cômica, como ocorre nas comédias, "castiga os costumes. Obriga-nos a cuidar imediatamente de parecer o que deveríamos ser, o que um dia acabaremos por ser verdadeiramente". (Bergson, 1980:18). O riso tem uma função útil de reprimir as excentricidades, de corrigir os desvios, de suavizar "tudo o que puder restar de rigidez mecânica na superfície do corpo social". (Bergson, 1980:18). Mas "dentro do convencionalismo dos finais cômicos, em geral [e nesta dramaturgia é a regra] percebemos uma liberação individual traduzida também em termos de reconciliação social". (Áreas, 1990:21). Ao trabalhar com um universo temático voltado à realidade quotidiana e prosaica das pessoas comuns, o seu desenlace, via de regra, tem sempre uma conclusão otimista com casamentos, reconciliações ou reconhecimentos. $\mathrm{O}$ aprendizado do espectador, através da experiência cômica, ocorre de modo indireto, "al aceptar el papel de escarnecedor se conjura el peligro de incurrir en el vicio. El espectador sentirá verguenza si identifica en él mismo el defecto cômico y sentirá ridicularizado a través del personaje; pero, a salvo, viviéndolo como una experiencia tangencial. La risa es una máscara que aparenta una 'otredad', que protege y defiende de ser señalado o inculpado." (Alatorre, 1986:77)

Ao defender os valores éticos e morais da burguesia estes textos apresentam personagens transgredindo em aspectos fundamentais para a moral dominante, no momento histórico em que foram encenados na União Operária. Sua transgressão pode colocar em risco o "caráter sagrado" do casamento, da família, da honra, do valor do trabalho, e do dinheiro que deve ser ganho, honestamente, e pelo trabalho.

As personagens, deste corpus textual, também são punidas por sua prepotência e egoísmo, principalmente quando estes vícios sociais colocam em risco a composição de uma família. Quanto às mulheres que apresentam certa rebeldia transgressora, sejam jovens esposas ou as moçoilas solteiras, ao correrem o risco de perder sua segurança representada pela figura masculina, do pai ou do marido, retrocedem em suas condutas e aprendem que o seu papel social é o de serem boas donas de casa e, principalmente, o de serem obedientes aos desejos de seus pais ou de seus maridos. E às sogras, estas perversas criaturas, são punidas

\footnotetext{
U 100 Dezembro 2006 - № 8
} 
com puxões de orelhas, purgantes, e com a devida autoridade do marido e do genro, que devem impor-lhe limites muito estreitos.

Ao lado dessas personagens "desviadas”, esse corpus textual representa personagens virtuosas, respeitosas das leis e valores morais e comportamentais que a sociedade burguesa considera adequados, e seus exemplos se contrapõem aos vícios e erros das personagens transgressoras e, conseqüentemente, são recompensadas ao final do texto, seja pelo casamento ou pela harmonização no ambiente familiar, e no caso dos homens, por adquirirem o domínio da casa e a autoridade ante suas esposas.

\section{Notas}

\footnotetext{
${ }^{1}$ A União Beneficente e Recreativa Operária foi criada pelos trabalhadores de Florianópolis em 1922, e teve suas atividades encerradas em 1951.

2 Comédias encenadas pelo Grupo Teatral João Dall' Grande Bruggmann e que foram recuperadas durante a pesquisa de campo: seis comédias em um ato, de autores portugueses: O Visconde da Rosa Branca, de J. Vieira Pontes; Ressonar sem Dormir (também conhecida como A Ordem é Ressonar, 39 da Oitava, Toribio Canuto), de Luiz F. de Castro Seromenho; de autores brasileiros: A Espada do General, de M. Piedade; Choro ou Rio, de Santos Junior; e duas do catarinense Horácio Nunes Pires: Grandes Manobras e A Prima. Duas comédias em dois atos: Casar para Morrer, de Afonso Gomes, português, e A Sorte Grande, de Pe. F. M. de Siqueira, brasileiro. E cinco comédias brasileiras em três atos: Cala a Boca, Etelvina, de Armando Gonzaga; Não me contes esse pedaço, de Miguel Santos; O Interventor, de Paulo de Magalhães e A Sogra, do catarinense Horácio Nunes Pires.

${ }^{3}$ Essa situação aparece nos textos: A Prima, Grandes Manobras e em A Espada do General.

${ }^{4}$ A Sogra. 30 ato. Cena IV. p. 408.

${ }^{5}$ Referências dos textos: Ressonar sem Dormir e A Espada do General.

${ }^{6}$ A Sorte Grande. 1o Ato. Cena VI, p. 8.

${ }^{7}$ A Sorte Grande. 1० Ato. Cena VI, p. 11

${ }^{8}$ A Sogra. 1० Ato. Cena III, p. 384

${ }^{9}$ A Sogra. 2o Ato. Cena IV, p. 400/4001

${ }^{10}$ Choro ou Rio? Cena IV, p.5

11 Choro ou Rio? Cena I, p. 2 e 3.

12 Grandes Manobras. Cena XII, p. 349.

${ }^{13}$ O Interventor. 1० Ato. Cena 1, p. 3.

${ }^{14}$ A Espada do General. Cena VII, p. 12.

${ }^{15}$ Casar para Morrer e O Interventor.

${ }^{16}$ A Espada do General. Cena I, p.4.

${ }^{17}$ Segundo Susan K. Besse, no "Brasil, em 1872, o emprego de 51,3\% das trabalhadoras fora da agricultura era o de empregadas domésticas; essa porcentagem caiu somente para 33,7\% em 1920 e cresceu ligeiramente para 36,1\% em 1940”, p. 157.

${ }^{18}$ Rosa criada, no texto O Visconde da Rosa Branca.

${ }^{19}$ Cala a Boca Etelvina! 1\% Ato. Cena XI, p. 29.

${ }^{20}$ Cala a Boca, Etelvina! 2o Ato. Cena X, p. 51.

${ }^{21}$ Ibidem, 3o Ato. Cena XII, p. 56.

22 A Sorte Grande. 2o Ato. Cena XVI, p. 32.
} 


\section{Bibliografia}

ALATORRE, Claudia Cecília. Analisis del drama. México: Gaceta, 1986.

ÁREAS, Vilma. Iniciação à Comédia. Rio de Janeiro: Zahar, 1990.

BERGSON, Henri. O Riso: ensaio sobre a significação do cômico. Rio de Janeiro: Zahar, 1980.

BESSE, Susan K. Modernizando a Desigualdade. São Paulo: Editora da Universidade de São Paulo, 1999.

GOMES, Affonso. Casar para Morrer! - O morto vivo! São Paulo: C. Teixeira, 1922.

GONZAGA, Armando. Cala a Boca, Etelvina! São Paulo: Livraria Teixeira, 1940.

JUNIOR, Santos. Choro ou Rio. (xerox).

MAGALHÃES, Paulo de. O Interventor. Rio de Janeiro: SBAT, 1931.

PEDRO, Joana. "O lugar da sogra na família moderna" in: Revista do Instituto Histórico e Geográfico de Santa Catarina. 3a fase. № 9. Florianópolis, 1990, p. 104 a 119.

PIEDADE, M. A Espada do General. Rio de Janeiro: Livraria Cruz Coutinho, 1905.

PIRES, Horácio Nunes. A Sogra. IN: Bastidores. Florianópolis: Gab.Typ. Catharinense, 1898.

. A Prima. in: Bastidores. Florianópolis: Gab. Typ. Catharinense, 1898.

Grandes Manobras. IN: Bastidores. Florianópolis: Gab. Typ. Catharinense, 1898.

PONTES, J. Vieira. O Visconde da Rosa Branca. (xerox).

SANTOS, Miguel. Não me Contes esse Pedaço. Rio de Janeiro: Pap. e Typ. Coelho, 1937.

SEROMENHO, Luiz F. de Castro. Ressonar sem Dormir. São Paulo: Livraria Teixeira, 1956.

SIQUEIRA, Pe. F. M. de. A Sorte Grande. Rio de Janeiro: Vozes Ltda., 1951.

SOIHET, Rachel. "História das Mulheres" in: CARDOSO, Ciro e VAINFAS, Ronaldo. Domínios da História. Rio de Janeiro: Campus, 1997, p. 275 a 311 